\title{
Bradycardia Following use of Intracameral Acetylcholine: A Case Report
}

\author{
Fatemeh Shams* \\ Tennent Institute of Ophthalmology, Glasgow, UK
}

In 2015 we published a case report of ventricular fibrillation occurring after the administration of intraocular phenylephrine [1] for floppy iris syndrome during phacoemulsification.

Recently we had an incidence of a different cardiac arrhythmia, this time bradycardia, a few minutes after the use of intracameral acetylcholine (Miochol ${ }^{\mathrm{TM}}-\mathrm{E}$ ) during cataract surgery.

This recent incidence has prompted us to review and again highlight some of the systemic adverse effects documented with use of such drugs during ocular surgery.

Acetylcholine is a neurotransmitter released at nerve endings in both the central and peripheral nervous system , a direct cholinergic agonist that binds and activates cholinergic receptors in the junction of the iris sphincter muscle and promotes pupillary constriction [2].

Systemically, acetylcholine mimics the cardiac effects of the parasympathetic nervous system resulting in reduced cardiac out and heart rate [2].

Amsler and Verrey [3] were the first to describe the use of acetylcholine chloride for intraoperative miosis after cataract surgery.

Further testing by Harley and Mishler [3] resulted in reaching the most effective concentration of the drug at 1:100 that is the concentration commonly used these days.

Acetylcholine is commonly used during phacoemulsification to ensure a round pupil at the end of the surgery, particularly after vitreous loss, but it is also useful in other settings such as during insertion of anterior chamber lenses, iridectomy, penetrating keratoplasty and trabeculectomy [3].

In the case we present, a hypertensive 72-year-old gentleman with narrow angle glaucoma underwent right phacoemulsification under local anaesthetic. His drug history included topical Timolol $0.25 \%$ twice a day to both eyes as well as perindopril $8 \mathrm{mg}$, amlodipine $5 \mathrm{mg}$ and bendroflumethiazide $2.5 \mathrm{mg}$ orally for hypertension. During the surgery, 3-clock hour zonular dehiscence was noted with no obvious vitreous loss. A capsular tension ring was inserted and the IOL placed in the bag. To ensure there was no unseen vitreous loss, $2 \mathrm{mls}$ of Michol ${ }^{\mathrm{TM}}-\mathrm{E}(10 \mathrm{mg} / \mathrm{ml})$ was instilled in- tracamerally after IOL insertion to produce miosis and ensure a round pupil was achieved.

A few minutes after the Michol ${ }^{\mathrm{TM}}$-E insertion, as the patient was being wheeled out of the operating room on finishing the procedure, he became light-headed and a quick check of his pulse on the pulse oxymeter showed a heart rate of 40 beats per minute. Fortuitously, an anesthetist was next door and was able to rapidly give the patient $1 \mathrm{mg}$ of Atropine.

Proof that this drug is responsible for adverse reactions is not simple. Bradycardia can occur spontaneously; and other drugs confound the issue.

The mechanism of action of the drug and the timing of the cardio-vascular event are reasons to accept that acetylcholine can be the sole cause of such a disastrous complication.

A literature search revealed 4 other case reports of bradycardia and hypotension secondary to intraocular acetylcholine use, the most recent one dated in 1991 [4-7].

It is prudent that as experienced ophthalmologists, we highlight to our juniors and younger trainees, the adverse systemic effects of topical and intracameral medication.

We also recommend the ready availability of anaesthetists experienced in cardio-pulmonary resuscitation and regular monitoring of patients heart rate during ocular surgery especially after the use of intracameral drugs such as acetylcholine or phenylpherine [1].

\section{Financial Support}

None to declare.

\section{Financial/Proprietary Interest}

None to declare.

*Corresponding author: Fatemeh Shams, Tennent Institute of Ophthalmology, Gartnavel General Hospital, 1053 Great western road, G12 OYN, Glasgow, UK

Accepted: November 28, 2020

Published online: November 30, 2020

Citation: Shams F (2020) Bradycardia Following use of Intracameral Acetylcholine: A Case Report. J Ophthalmic Surg 3(1):25-26 


\section{References}

1. Shams F, Jafari A, Mansfield D (2015) Cardiovascular hazard of intracameral phenylepherine. J Cataract Refract Surg 41: 20212022.

2. Forrester JV, Dick A, McMenamin P, et al. (2016) The eye: Basic sciences in practive ( $4^{\text {th }}$ edn). 568.

3. Beasley H (1972) Mitotics in cataract surgery. Arch Ophthalmol 88: 49-51.

4. Babinski M, Smith B, Wickerham EP (1976) Hypotension and bradycardia following intraocular acetylcholine injection. Report of a case. Arch Ophthalmol 94: 675-676.
5. Brinkley JR Jr, Henrick A (1984) Vascular hypotension and bradycardia following intraocular injection of acetylcholine during cataract surgery. Am J Ophthalmol 97: 40-42.

6. Hagan JC (1990) Severe bradycardia and hypotension following intraocular acetylcholine in a patient who previously tolerated the medication. Mo Med 87: 231-233.

7. Erickson SR, Yousuf MJ (1991) Hypotension and bradycardia possibly associated with intraocular injection of acetylcholine. DICP 25: 1178-1180.

DOI: $10.36959 / 587 / 593$

Copyright: (C) 2020 Shams F. This is an open-access article distributed under the terms of the Creative Commons Attribution License, which permits unrestricted use, distribution, and reproduction in any medium, provided the original author and source are credited. 